\title{
Carbon Kinetic Isotope Effects in the Gas Phase Reactions of Light Alkanes and Ethene with the OH Radical at $296 \pm 4 \mathrm{~K}$
}

\author{
Rebecca S. Anderson, ${ }^{*}$ Lin Huang, ${ }^{\dagger}$ Richard Iannone, ${ }^{\ddagger}$ Alexandra E. Thompson,,$~ a n d ~$ \\ Jochen Rudolph \\ Centre for Atmospheric Chemistry and Chemistry Department, York University, 4700 Keele Street, \\ Toronto, Ontario M3J 1P3, Canada, and Meteorological Service of Canada, Environment Canada, \\ 4905 Dufferin Street, Toronto, Ontario M3H 5T4, Canada
}

Received: June 28, 2004; In Final Form: October 4, 2004

\begin{abstract}
The carbon kinetic isotope effects (KIEs) of the room-temperature reactions of several light alkanes and ethene with $\mathrm{OH}$ radicals were measured in a $30 \mathrm{~L}$ PTFE reaction chamber at ambient pressure using gas chromatography coupled with online combustion and isotope ratio mass spectrometry (GCC-IRMS). For simplicity, KIEs are reported in per mil according to $\epsilon(\% o)=\left(k_{12} / k_{13}-1\right) \times 1000$. The following average KIEs were obtained, (all in \%o): ethane, $8.57 \pm 1.95$; propane, $5.46 \pm 0.35 ; n$-butane, $5.16 \pm 0.67$; methylpropane, $8.45 \pm 1.49 ; n$-pentane, $2.85 \pm 0.79$; methylbutane, $2.91 \pm 0.43$; $n$-hexane, $2.20 \pm 0.07$; $n$-heptane, $1.96 \pm 0.26$; $n$-octane, $2.13 \pm 0.39$; cyclopentane, $1.84 \pm 0.13$; cyclohexane, $4.46 \pm 0.51$; methylcyclopentane, $1.77 \pm 0.53$; ethene, $18.6 \pm 2.9$. As well, the room-temperature rate constant for the reaction of methylcyclopentane $+\mathrm{OH}$, not previously reported in the literature, was determined using relative rates: $(8.6 \pm 2.2) \times 10^{-12} \mathrm{~cm}^{3}$ molecule ${ }^{-1} \mathrm{~s}^{-1}$, including the estimated $25 \%$ uncertainty in the rate constant for cyclopentane $+\mathrm{OH}$. KIE values for propane, $n$-butane and $n$-hexane have been reported previously $[J$. Geophys. Res. [Atmos.] 2000, 105, 29329]. Our KIE for $n$-hexane is in agreement with the previous measurement, but our values for propane and $n$-butane are both higher. The dependence between the KIE and chemical structure is discussed, and a method for estimating unknown carbon KIEs for the reactions of light alkanes with $\mathrm{OH}$ radicals is presented. With only one exception, predictions using this method agree within a factor of 2 of the experimental KIE results.
\end{abstract}

\section{Introduction}

Light alkanes and alkenes are present in the atmosphere from high parts per billion by volume (ppbV) levels in urban areas to mid- to low-parts per trillion by volume (pptV) levels in remote locations. Both alkanes and ethene are emitted from primarily anthropogenic sources. ${ }^{2,3}$ Oxidation by $\mathrm{OH}$ radicals is the primary removal mechanism for alkanes and ethene from the atmosphere, although the reaction of ethene with ozone also has a significant impact on ethene loss from the lower troposphere. Reactions of hydrocarbons with $\mathrm{OH}$ radicals have been widely studied. ${ }^{4}$ These reactions are of atmospheric importance, producing precursors for ozone formation and atmospheric peroxides as well as aldehydes and organic nitrates.

The usefulness of stable carbon isotope ratio measurements of nonmethane hydrocarbons (NMHC) to study atmospheric processes involving NMHC has been demonstrated in a number of publications. ${ }^{1,5-11}$ To utilize isotope ratio measurements in this manner, reliable measurements of the isotopic fractionations associated with the atmospheric loss of NMHC are essential. In this paper, laboratory measurements of the carbon kinetic isotope effects (KIEs) associated with the reactions of light $\mathrm{C}_{2}-$ $\mathrm{C}_{8}$ alkanes and ethene with $\mathrm{OH}$ radicals are presented. To the authors' knowledge, the carbon KIE for the reaction of ethene

\footnotetext{
* Corresponding author. E-mail: rebeccah@yorku.ca.

Meteorological Service of Canada.

$\doteqdot$ Also: Institut für Chemie und Dynamik der Geosphäre, ICG-II, Troposphäre, Forschungszentrum Jülich, Germany.

${ }^{\S}$ Now at Ecosystem Science, University of California, Berkeley, CA.
}

with $\mathrm{OH}$ radicals has not yet been reported. Ethene is somewhat unique in tropospheric processes due to its high concentrations and, compared to other alkenes, relatively low reactivity. The only laboratory measurements of alkane-OH carbon KIEs previously reported were for reactions with propane, $n$-butane, and $n$-hexane. ${ }^{1}$ In this paper we present measurements of the stable carbon KIEs for the reactions of ethane and several alkanes with $\mathrm{OH}$ in the gas phase and use the results to study the dependence between chemical structure and KIE.

\section{Measurement}

The OH-reaction KIEs of ethene and 12 different alkanes were studied in synthetic air at atmospheric pressure at $296 \pm$ $4 \mathrm{~K}$. Between one and three alkanes were studied in each of the 16 experiments conducted. Ethene was studied in only one experiment together with two alkanes. Some experiments also included aromatic hydrocarbons; however, the KIEs obtained for aromatic compounds are not included in this paper. The KIEs were measured using a previously described method ${ }^{12}$ so only a brief outline of the procedure follows. Hydrocarbons were injected into a $30 \mathrm{~L}$ PTFE reaction chamber to generate mixing ratios between 13 and $325 \mathrm{ppmV}$. The hydrocarbons were $97+\%$ grade chemicals from Sigma Aldrich, Air Products, and Matheson Gas. $\mathrm{OH}$ radicals were generated in situ through photolysis of isopropyl nitrite in the presence of high parts per million by volume $(\mathrm{ppmV}) \mathrm{NO}$. The isopropyl nitrite was prepared in a manner similar to the synthesis described by Noyes ${ }^{13}$ and the $\mathrm{NO}$ was added from a $1 \% \mathrm{NO}$ in $\mathrm{N}_{2}$ mixture from Air 
Products. Photolysis was achieved through the use of individually controllable UV lights (emitting at $\lambda_{\max }=350 \mathrm{~nm}$ ) positioned next to the chamber. Using an automated sampling system, $5 \mathrm{~mL}$ samples from the chamber were analyzed by gas chromatography coupled with online combustion and isotope ratio mass spectrometry (GCC-IRMS).

The samples were separated by gas chromatography (GC) using an HP-1 column (Agilent Technologies, $60 \mathrm{~m}, 0.32 \mathrm{~mm}$ i.d., $5 \mu \mathrm{m}$ film thickness) and, using 2D chromatography where necessary for further separation, either a GS-GasPro PLOT column (J\&W Scientific Inc., $60 \mathrm{~m}, 0.32 \mathrm{~mm}$ i.d.) or a PoraPlot Q column (Chromatographic Specialties Inc., $60 \mathrm{~m}, 0.32 \mathrm{~mm}$ i.d.). The GC temperature program varied depending on the hydrocarbons being separated, but all began at $243 \mathrm{~K}$. An electronic pressure control unit maintained the carrier gas flow rate (He, Air Products, $99.995 \%$ ) at $1.5 \mathrm{~mL} \mathrm{~min}{ }^{-1}$. Approximately $0.3 \mathrm{~mL} \mathrm{~min}^{-1}$ of the GC effluent went to a Saturn 2000 ion trap mass spectrometer for peak identification and peak purity verification. The remaining $1.2 \mathrm{~mL} \mathrm{~min}^{-1}$ of the effluent passed through a combustion interface and then a Nafion permeation dryer for conversion to carbon dioxide and water removal. Approximately $0.4 \mathrm{~mL} \mathrm{~min}^{-1}$ of this flow was then transferred via an open split to the ion source of the isotope ratio mass spectrometer (Finnigan MAT 252) for stable carbon isotope ratio measurement.

For each experiment, at least two measurements were made with the reaction chamber in the dark (i.e., no generation of $\mathrm{OH}$ radicals), but otherwise under conditions identical to the experiments. From these prereaction measurements, not including the results for ethane, the average relative standard deviation of the concentration values for each experiment was $1.6 \%$, with all values lower than $6.5 \%$. The average standard deviation of the $\delta^{13} \mathrm{C}$ values for each experiment was $0.13 \%$, and all standard deviations were lower than $0.4 \%$. After initiating the reaction by turning on the UV lamps, 3-14 samples were analyzed. All measurements, both before and after the reaction initiation took approximately $1.5-2 \mathrm{~h}$. Hydrocarbon concentrations at the end of the experiment were generally depleted to $<50 \%$ of their initial values with the exception of ethane, which had an average $25 \%$ depletion due to its slower reaction rate in comparison to that of the other hydrocarbons being studied.

Using the traces generated by the IRMS, stable carbon isotope ratios and concentrations were determined. Stable carbon isotope ratios were calibrated against an offline $\mathrm{CO}_{2}$ standard before and after each run to maintain consistent isotope ratio measurement within an experiment. Absolute carbon isotope ratio determination was not necessary, as only relative changes in isotope ratio are necessary for KIE measurements. Hydrocarbon concentrations were derived from the abundance of the ${ }^{12} \mathrm{C}$ atoms in the sample. The $\mathrm{KIE}$ is defined as the ratio of the rate constants for the species containing only ${ }^{12} \mathrm{C}$ atoms and those containing a ${ }^{13} \mathrm{C}$ atom, $k_{12} / k_{13}$. This ratio can be determined from the slope of the linear least-squares fit of the relationship between concentration and isotope ratios described ${ }^{12}$ as

$$
\begin{aligned}
& \ln \left({ }^{12} \mathrm{C}_{t} /{ }^{12} \mathrm{C}_{0}\right)= \\
& k_{12} / k_{13} /\left(1-k_{12} / k_{13}\right) \ln \left[\left({ }^{13} \mathrm{C}_{t} /{ }^{12} \mathrm{C}_{t}\right) /\left({ }^{13} \mathrm{C}_{0} /{ }^{12} \mathrm{C}_{0}\right)\right]
\end{aligned}
$$

where $\mathrm{C}_{t}$ and $\mathrm{C}_{0}$ correspond to the abundance of carbon atoms at time $t$ and $t=0$, respectively. The experimental uncertainty for an individual experiment is determined from the uncertainty in the slope of (1).

In the experiments containing ethane, poor reproducibility was found in the measurements of the ${ }^{12} \mathrm{C}$ abundance for the ethane peak. In contrast to this, the average standard deviation of the isotope ratios of the three or more prereaction measurements made during each of the four ethane KIE experiments was only $0.15 \%$ o. This shows that the problem that plagued the concentration measurements had no significant effect on the stable carbon isotope ratio determinations. The most likely explanation is insufficient and yet nonisotopically fractionating trapping of ethane, which has the highest volatility of all studied compounds, in the low-temperature preconcentration trap. To avoid the large uncertainties that would result from the high variability of the ethane concentration values, we used a slightly different procedure for the determination of the ethane KIE.

The dependence between time, $\mathrm{OH}$-radical concentration, and the stable carbon isotope ratio of ethane can be described by the following equation:

$$
\frac{{ }^{12} \mathrm{C}_{\text {ethane }, t}}{{ }^{13} \mathrm{C}_{\text {ethane }, t}}=\frac{{ }^{12} \mathrm{C}_{\text {ethane }, 0} \exp \left(-{ }^{12} k_{\text {ethane }} \int_{0}^{t}[\mathrm{OH}] \mathrm{d} t\right)}{{ }^{13} \mathrm{C}_{\text {ethane }, 0} \exp \left(-{ }^{13} k_{\text {ethane }} \int_{0}^{t}[\mathrm{OH}] \mathrm{d} t\right)}
$$

or

$$
\begin{aligned}
\ln \left(\frac{{ }^{12} \mathrm{C}_{\text {ethane }, t}}{{ }^{13} \mathrm{C}_{\text {ethane }, t}}\right) & =\ln \left(\frac{{ }^{12} \mathrm{C}_{\text {ethane }, 0}}{{ }^{13} \mathrm{C}_{\text {ethane }, 0}}\right)+ \\
& \left({ }^{13} k_{\text {ethane }}-{ }^{12} k_{\text {ethane }}\right) \int_{0}^{t}[\mathrm{OH}] \mathrm{d} t
\end{aligned}
$$

For each of the data points $\int_{0}^{t}[\mathrm{OH}] \mathrm{d} t$ can be determined from the change in propane concentration, which in our experiments has been measured simultaneously with the ethane isotope ratios:

$$
\int_{0}^{t}[\mathrm{OH}\} \mathrm{d} t=\frac{1}{{ }^{12} k_{\text {propane }}} \ln \left(\frac{{ }^{12} \mathrm{C}_{\text {propane }, 0}}{{ }^{12} \mathrm{C}_{\text {propane }, t}}\right)
$$

and we obtain

$$
\begin{aligned}
\ln \left(\frac{{ }^{12} \mathrm{C}_{\text {ethane }, t}}{{ }^{13} \mathrm{C}_{\text {ethane }, t}}\right) & =\ln \left(\frac{{ }^{12} \mathrm{C}_{\text {ethane }, 0}}{{ }^{13} \mathrm{C}_{\text {ethane }, 0}}\right)+ \\
& \left({ }^{13} k_{\text {ethane }}-{ }^{12} k_{\text {ethane }}\right) \frac{1}{{ }^{12} k_{\text {propane }}} \ln \left(\frac{{ }^{12} \mathrm{C}_{\text {propane }, 0}}{{ }^{12} \mathrm{C}_{\text {propane }, t}}\right)
\end{aligned}
$$

Rearranging and dividing by ${ }^{12} k_{\text {ethane }}$ gives the following equation, which allows for the determination of the KIE from plots analogous to our standard procedure.

$$
\begin{aligned}
& \frac{{ }^{12} k_{\text {ethane }}}{{ }^{12} k_{\text {propane }}} \ln \left(\frac{{ }^{13} \mathrm{C}_{\text {propane }, t}}{{ }^{12} \mathrm{C}_{\text {propane }, 0}}\right)= \\
& \frac{{ }^{12} k_{\text {ethane }} /{ }^{13} k_{\text {ethane }}}{1-{ }^{12} k_{\text {ethane }} /{ }^{13} k_{\text {ethane }}} \ln \left[\left(\frac{{ }^{13} \mathrm{C}_{\text {ethane }, t}}{{ }^{12} \mathrm{C}_{\text {ethane }, t}}\right) /\left(\frac{{ }^{13} \mathrm{C}_{\text {ethane }, 0}}{{ }^{12} \mathrm{C}_{\text {ethane }, 0}}\right)\right]
\end{aligned}
$$

The disadvantage of (2e) is the propagation of the uncertainty of ${ }^{12} k_{\text {ethane }} /{ }^{12} k_{\text {propane }}$ from literature values ${ }^{4}$ into the error of the KIE.

Relative reaction rate analyses were performed for each experiment to verify that NMHC loss was primarily due to reaction with $\mathrm{OH}$ radicals. For the ethene $\mathrm{KIE}$, the relative rate analysis showed that the loss rate of ethene was approximately 2 times greater than expected from the loss rates of the two alkanes present in the same experiment. This can be explained by the reaction of ethene with ozone, produced in the chamber during the course of the reaction. Consequently, a correction 
was applied to the results to determine the OH-reaction KIE. Knowing that the change in stable carbon isotope ratio over a given time $t$ for an alkene $z$ is dependent on both the $\mathrm{OH}$ - and $\mathrm{O}_{3}$-reaction KIEs, the radical concentrations and the rate constants for each reaction are such that

$$
\delta_{z}-{ }^{0} \delta_{z}=t\left({ }^{\mathrm{OH}} k_{z}[\mathrm{OH}]{ }^{\mathrm{OH}} \epsilon_{z}+{ }^{\mathrm{O}_{3}} k_{z}\left[\mathrm{O}_{3}\right]^{\mathrm{O}_{3}} \epsilon_{z}\right)
$$

Here $\delta_{z}$ and ${ }^{0} \delta_{z}$ are the stable carbon isotope ratios of compounds $z$ at time $t$ and $t=0$, respectively, and $[\mathrm{OH}]$ and $\left[\mathrm{O}_{3}\right]$ are the average concentrations for the time period between $t=0$ and $t$. To correct for the impact of the presence of ozone, a relative rate analysis was used to compare the loss rate of ethene due to reaction with both $\mathrm{OH}$ radicals and ozone, with the loss rate of cyclohexane due to reaction with only $\mathrm{OH}$ radicals according to the following:

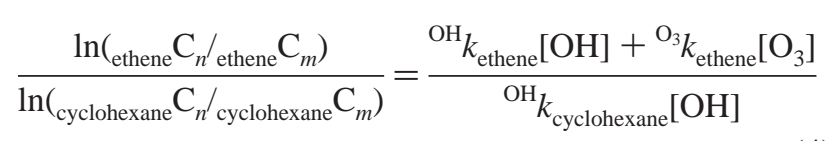

The rate constant for the reaction of ozone with cyclohexane is sufficiently small that even when $\left[\mathrm{O}_{3}\right]$ is as high as $10^{8}[\mathrm{OH}]$, ${ }^{\mathrm{OH}} k_{\text {cyclohexane }}[\mathrm{OH}] \gg \mathrm{O}_{3} k_{\text {cyclohexane }}\left[\mathrm{O}_{3}\right]$. Because in our experiment the ratio of $\left[\mathrm{O}_{3}\right] /[\mathrm{OH}]$ was well below $10^{8}$ (see below), this reaction can be ignored without introducing bias. This allows for the determination of the ratio $\left[\mathrm{O}_{3}\right] /[\mathrm{OH}]$ using (4) for each interval between two measurements $n$ and $m$ within an experiment. The average $\left[\mathrm{O}_{3}\right] /[\mathrm{OH}]$ ratio was $(4.4 \pm 2.0) \times 10^{6}(1 \sigma$ standard deviation). Using eq 3 with the literature rate constant values from Atkinson and Arey, ${ }^{4}$ the $\mathrm{O}_{3} \epsilon_{\text {ethene }}$ from Iannone et al. ${ }^{14}$ of $(18.85 \pm 1.10) \%$, and $[\mathrm{OH}]$ and $\left[\mathrm{O}_{3}\right]$ determined from the loss rate of cyclohexane and (4), we determined the ${ }^{\mathrm{OH}} \epsilon_{\text {ethene }}$ value for each interval and then averaged them.

\section{Results}

Using the method described for determining the ethene- $\mathrm{OH}$ KIE from our measurements, we determined the KIE for the reaction of ethene $+\mathrm{OH}$ to be $(18.6 \pm 2.9) \%$. Selecting other differently defined intervals for the calculation led to results with larger uncertainties that were statistically not different from the above KIE value; thus this value is a fair representation of the KIE value for the reaction of ethene $+\mathrm{OH}$.

The results of the alkane KIE measurements are summarized in Table 1. A summary of the resultant experimental rate constants and uncertainties from the reaction rate analysis is also included in Table 1 . The uncertainty for each experimentally derived ${ }^{\mathrm{OH}_{k}}$ was determined using the standard error of the relative rate analyses and the literature rate constant and its uncertainty of the reference compound. ${ }^{4}$ All ${ }^{\mathrm{OH}} k$ calculated from the relative rate analysis are in agreement with the literature rate constants (Table 2). The average KIEs and the error of the mean KIE for each hydrocarbon were averaged and compiled in Table 2. The errors of the mean were determined using $1 \sigma(n$ $-1)^{-1 / 2}$, where $1 \sigma$ is the $1 \sigma$ standard deviation of the KIE values and $n$ is the number of KIE measurements made. For hydrocarbons measured more than once, but excluding the KIE measurements for ethane due to its considerable uncertainties, the average error of the mean KIEs was $\pm 0.44 \%$ o. Also included in Table 2 is the average experimentally determined rate constant. For compounds with more than one measurement, the uncertainty reported for the experimental rate constant is the $1 \sigma$ standard deviation of the mean.
TABLE 1: Measurements of the Kinetic Isotope Effects for the Reactions of Alkanes with OH Radicals at 1013 mbar

\begin{tabular}{|c|c|c|c|c|}
\hline alkane & $\begin{array}{l}\text { temp, } \\
\pm 3 \mathrm{~K}\end{array}$ & $\begin{array}{l}\epsilon^{a} \\
\% o\end{array}$ & $R^{2}$ & 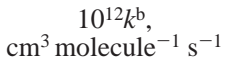 \\
\hline \multirow[t]{4}{*}{ ethane } & $295^{c}$ & $8.5 \pm 3.1$ & 0.663 & \\
\hline & $296^{c}$ & $6.6 \pm 2.2$ & 0.738 & \\
\hline & $297^{c}$ & $13.4 \pm 3.9$ & 0.969 & \\
\hline & $298^{c}$ & $5.8 \pm 1.7$ & 0.942 & \\
\hline \multirow[t]{5}{*}{ propane } & 293 & $5.4 \pm 2.5$ & 0.614 & $1.2 \pm 0.3^{d}$ \\
\hline & $295^{c}$ & $4.7 \pm 0.5$ & 0.895 & \\
\hline & $296^{c}$ & $5.2 \pm 0.4$ & 0.920 & \\
\hline & $297^{c}$ & $6.6 \pm 0.3$ & 0.974 & \\
\hline & $298^{c}$ & $5.3 \pm 0.5$ & 0.941 & \\
\hline \multirow[t]{4}{*}{ methylpropane } & 292 & $5.0 \pm 0.5$ & 0.960 & $2.1 \pm 0.4^{e}$ \\
\hline & 293 & $11.2 \pm 2.0$ & 0.884 & $1.8 \pm 0.4^{f}$ \\
\hline & 293 & $8.7 \pm 1.8$ & 0.775 & $2.1 \pm 0.6^{g}$ \\
\hline & 293 & $9.0 \pm 2.4$ & 0.740 & $1.8 \pm 0.5^{g}$ \\
\hline$n$-butane & 292 & $5.2 \pm 0.7$ & 0.952 & $2.5 \pm 0.6^{h}$ \\
\hline \multirow[t]{2}{*}{ cyclopentane } & 293 & $1.9 \pm 0.3$ & 0.841 & $4.4 \pm 1.1^{d}$ \\
\hline & 293 & $1.8 \pm 0.3$ & 0.908 & $5.1 \pm 1.3^{d}$ \\
\hline \multirow[t]{2}{*}{ methylbutane } & 293 & $2.6 \pm 0.3$ & 0.935 & $3.4 \pm 0.8^{i}$ \\
\hline & 298 & $3.2 \pm 0.3$ & 0.965 & $3.4 \pm 0.7^{j}$ \\
\hline \multirow[t]{2}{*}{$n$-pentane } & 292 & $3.4 \pm 0.6$ & 0.907 & $3.6 \pm 0.7^{e}$ \\
\hline & 293 & $2.3 \pm 0.1$ & 0.988 & $3.7 \pm 0.8^{k}$ \\
\hline cyclohexane & 298 & $4.5 \pm 0.5$ & 0.951 & $7.2 \pm 2.3^{l}$ \\
\hline \multirow[t]{2}{*}{ methylcyclopentane } & 293 & $2.2 \pm 0.3$ & 0.907 & $8.6 \pm 2.2^{g}$ \\
\hline & 293 & $1.4 \pm 0.2$ & 0.935 & $8.6 \pm 2.2^{g}$ \\
\hline \multirow[t]{3}{*}{$n$-hexane } & 292 & $2.3 \pm 0.5$ & 0.803 & $3.1 \pm 0.7^{k}$ \\
\hline & 293 & $2.2 \pm 0.2$ & 0.978 & $4.4 \pm 0.9^{k}$ \\
\hline & 300 & $2.1 \pm 0.6$ & 0.637 & $6.1 \pm 1.2^{k}$ \\
\hline \multirow[t]{3}{*}{$n$-heptane } & 292 & $2.3 \pm 0.2$ & 0.974 & $7.0 \pm 1.8^{m}$ \\
\hline & 293 & $1.6 \pm 0.2$ & 0.945 & $6.1 \pm 1.2^{k}$ \\
\hline & 300 & $1.94 \pm 0.05$ & 0.997 & $7.3 \pm 1.5^{k}$ \\
\hline \multirow[t]{4}{*}{$n$-octane } & 292 & $2.0 \pm 0.3$ & 0.901 & $7.8 \pm 1.6^{k}$ \\
\hline & 292 & $1.85 \pm 0.07$ & 0.922 & $8.6 \pm 1.7^{k}$ \\
\hline & 292 & $3.1 \pm 0.2$ & 0.983 & $8.8 \pm 2.2^{m}$ \\
\hline & 300 & $1.6 \pm 0.2$ & 0.926 & $9.1 \pm 1.8^{k}$ \\
\hline
\end{tabular}
Total Pressure in Air

${ }^{a}$ Error given is the uncertainty in the plot of eq 1 with the exception of the ethane data, which includes the literature uncertainty of ${ }^{12} k_{\text {propanel }}$ ${ }^{12} k_{\text {ethane. }}{ }^{4}{ }^{b}$ Calculated using literature rate constants and uncertainties for the reference compound ${ }^{4}$ and the standard error of the relative rate analysis. ${ }^{c}$ Ethane concentration loss rate corrected relative to propane. ${ }^{d}$ Methylpropane used as reference compound. ${ }^{e} n$-Butane used as reference compound. ${ }^{f}$ Propane used as reference compound. ${ }^{g}$ Cyclopentane used as reference compound. ${ }^{h} n$-Pentane used as reference compound. ${ }^{i}$ Benzene used as reference compound. ${ }^{j}$ Cyclohexane used as reference compound. ${ }^{k}$ Toluene used as reference compound. ${ }^{l} \mathrm{Me}-$ thylbutane used as reference compound. ${ }^{m} p$-Xylene used as reference compound.

\section{Discussion}

Alkane KIEs. The KIE of the reaction of ethane with $\mathrm{OH}$ radicals is by far the most uncertain of the alkane KIEs. This is mainly due to the very slow reaction rate of ethane with $\mathrm{OH}$. The difficulty of maintaining reactant stability within the chamber for extended time periods while photolyzing large concentrations of isopropyl nitrite is a very real limitation of the method. As a result, the reactions involving ethane never had more than $50 \%$ depletion in ethane concentration and an average depletion of only $26 \%$. Additionally, there was poor reproducibility in the ethane concentration measurements.

The KIEs measured for the reactions of propane, $n$-butane, and $n$-hexane with $\mathrm{OH}$ radicals were all larger than the KIEs reported by Rudolph et al. ${ }^{1}$ The literature value $(1.41 \pm 0.92) \%$ o for the $n$-hexane-OH KIE has a considerable uncertainty and consequently the difference of $(0.79 \pm 0.92) \%$ o is statistically not significant. Of the five propane-OH KIE measurements presented here, only one was in agreement with the literature value $(3.44 \pm 0.26) \%$. The average KIE of $(5.46 \pm 0.35) \%$ o reported here is $(2.02 \pm 0.44) \%$ o greater. A similar difference of $(2.32 \pm 0.69) \%$ exists between the only measurement for the $n$-butane-OH KIE in this work, $(5.16 \pm 0.67) \%$ and the 
TABLE 2: Summary of the Kinetic Isotope Effect Measurements for the Reactions of Alkanes with $\mathrm{OH}$ Radicals at $296 \pm 4 \mathrm{~K}$ at Total Pressure 1013 mbar in Air

\begin{tabular}{|c|c|c|c|c|c|}
\hline hydrocarbon & $\begin{array}{c}\text { average } \epsilon, \\
\% o\end{array}$ & $\begin{array}{c}\text { error of mean, } \\
\% o\end{array}$ & $\begin{array}{c}95 \% \text { confidence } \\
\text { interval, } \%\end{array}$ & $\begin{array}{c}10^{12} k_{\text {experimental }}{ }^{d} \\
\mathrm{~cm}^{3} \text { molecule }^{-1} \mathrm{~s}^{-1}\end{array}$ & $\begin{array}{c}10^{12} k_{\text {literature, }}{ }^{4} \\
\mathrm{~cm}^{3} \text { molecule }^{-1} \mathrm{~s}^{-1}\end{array}$ \\
\hline ethane $^{a}$ & 8.57 & 1.95 & $5.26-11.89$ & & $0.25 \pm 0.05$ \\
\hline propane & 5.46 & 0.35 & $4.85-6.07$ & $1.2 \pm 0.3^{e}$ & $1.1 \pm 0.2$ \\
\hline$n$-butane ${ }^{b}$ & 5.16 & $0.67^{c}$ & & $2.5 \pm 0.6$ & $2.4 \pm 0.5$ \\
\hline methylpropane & 8.45 & 1.49 & $5.93-10.97$ & $2.0 \pm 0.2$ & $2.1 \pm 0.4$ \\
\hline$n$-pentane & 2.85 & 0.79 & $1.76-3.95$ & $3.7 \pm 0.1$ & $3.8 \pm 1.0$ \\
\hline methylbutane & 2.91 & 0.43 & $2.31-3.51$ & $3.4 \pm 0.1$ & $3.6 \pm 1.1$ \\
\hline$n$-hexane & 2.20 & 0.07 & $2.09-2.32$ & $4.5 \pm 1.5$ & $5.2 \pm 1.0$ \\
\hline$n$-heptane & 1.96 & 0.26 & $1.55-2.38$ & $6.8 \pm 0.6$ & $6.8 \pm 1.4$ \\
\hline$n$-octane & 2.13 & 0.39 & $1.47-2.80$ & $8.6 \pm 0.6$ & $8.1 \pm 1.6$ \\
\hline cyclopentane & 1.84 & 0.13 & $1.66-2.02$ & $4.8 \pm 0.6$ & $5.0 \pm 1.2$ \\
\hline cyclohexane $^{b}$ & 4.46 & $0.51^{c}$ & & $7.2 \pm 2.3$ & $7.0 \pm 1.4$ \\
\hline methylcyclopentane & 1.77 & 0.53 & $1.04-2.50$ & $8.6 \pm 2.2$ & $5.7 \pm 2.8^{f}$ \\
\hline
\end{tabular}

${ }^{a} k_{\text {experimental }}$ cannot be determined as concentration loss rate was determined relative to propane. ${ }^{b}$ Confidence interval cannot be calculated as results are available for only one experiment. ${ }^{c}$ Error is uncertainty in the slope of eq $1 .{ }^{d}$ Mean $k$ calculated using relative rate analysis; uncertainties show the error of the mean for compounds with multiple measurements. ${ }^{e}$ Only one value available. ${ }^{f}$ Estimated using the structure-reactivity relationship method outlined in Atkinson, with error estimated at $\pm 50 \% .{ }^{15}$

literature value $(2.84 \pm 0.17) \%$. Due to the nature of the KIE measurement method, it is entirely possible that even with multiple measurements, a persistent systematic leak or diffusional loss from the reaction chamber over the duration of a reaction may have led to consistently lower KIE measurements. The other two previously measured alkane-OH KIEs, propane and $n$-hexane, were measured 5 and 3 times, respectively, in this work. From the previous measurements to this work, there is a systematic increase in the average KIEs that is similar to the increase in the $n$-butane KIE. Due to more thorough chamber leak-testing procedures and a more reliable cryogenic trapping system than in the system used by Rudolph et al., ${ }^{1}$ we have reason to believe that these more recent $\mathrm{OH}$ KIE measurements are more reliable for these slower-reacting alkanes than those previously reported.

As a first approximation, the average room-temperature KIEs of the $n$-alkanes reported in Table 2 can be described using an inverse dependence on the number of carbon atoms $N_{\mathrm{C}}: \epsilon(\%)$ $=(16.6 \pm 1.0) N_{\mathrm{C}}{ }^{1-}$ with an $R^{2}$ value of 0.756 . The exclusion of the ethane data point, which has the highest uncertainty, has only a small effect, giving $\epsilon(\% \circ)=(16.1 \pm 0.7) N_{\mathrm{C}}{ }^{-1}$ and an $R^{2}$ value of 0.848 . On average, KIEs derived from this relation will be nearly $70 \%$ higher than those calculated from the previously published dependence $\epsilon(\% o)=(10.0 \pm 2.2) N_{\mathrm{C}}{ }^{-1}{ }^{1}$

For one of the alkanes measured, methylcyclopentane, there is no ${ }^{\mathrm{OH}_{k}} \mathrm{value}$ reported in the literature. Using the relative rate technique relative to cyclopentane from two separate experiments, our rate constant for this reaction is $(8.6 \pm 2.2) \times 10^{-12}$ $\mathrm{cm}^{3}$ molecule $\mathrm{s}^{-1} \mathrm{~s}^{-1}$, including the estimated $25 \%$ uncertainty in the rate constant for cyclopentane $+\mathrm{OH}$.

${ }^{13}$ C Structure-Reactivity Relationship (SRR). Although it serves as a good first approximation, the simple $N_{\mathrm{C}}{ }^{-1}$ dependence is limited to the $n$-alkanes, and it does not differentiate between fractionations due to reactions at different types of carbon atoms: primary, secondary, and in the case of branched alkanes, tertiary. As discussed by Atkinson, ${ }^{15}$ the hydrogen-abstraction rate constant for an alkane can be described using the site-specific rate constants for the $\mathrm{H}$-atom abstraction from primary, secondary, and tertiary carbon atoms and the individual substituent factors $F(\mathrm{X})=1.00$ and $F(\mathrm{Y})=$ $F(\mathrm{Z})=1.23$, where substituents are $\mathrm{X}=-\mathrm{CH}_{3}, \mathrm{Y}=-\mathrm{CH}_{2}-$, and $\mathrm{Z}=>\mathrm{CH}-$. As an example, the rate constant for $n$-butane can be described as

$$
k=k_{1^{\circ}} F(\mathrm{Y})+k_{2^{\circ}} F(\mathrm{X}) F(\mathrm{Y})+k_{2^{\circ}} F(\mathrm{X}) F(\mathrm{Y})+k_{1^{\circ}} F(\mathrm{Y})
$$

where $k_{1}$ and $k_{2}$ are the group rate constants for reactions at $-\mathrm{CH}_{3}$ and $-\mathrm{CH}_{2}-$ groups, respectively. Here we will extend the concept of group specific reaction rate constants by introducing carbon isotope specific group rate constants, $k_{1^{\circ} 13}$, $k_{2^{\circ} 13}$, and $k_{3^{\circ} 13}$. Such a concept has already been successfully used for deuterium labeled alkanes. ${ }^{16-18}$ The value for $F$ is assumed to be independent of the carbon isotope composition of the hydrocarbon. Considering that the literature recommendation $^{15}$ is $F(\mathrm{Y})=F(\mathrm{Z})$, this should be a valid assumption for the degree of accuracy possible for such approximations.

For $n$-alkane reactions in which the compound has only ${ }^{12} \mathrm{C}$ atoms, the rate constant can be written as the sum of the individual reaction rate constants and numbers of primary and secondary carbon atoms as follows:

$N_{\mathrm{C}}=2 \quad k_{12}=2 k_{1^{\circ} 12}$

$N_{\mathrm{C}}=3 \quad k_{12}=2 F k_{1^{\circ} 12}+k_{2^{\circ} 12}$

$N_{\mathrm{C}} \geq 4 \quad k_{12}=2 F k_{1^{\circ} 12}+\left[2 F+\left(N_{\mathrm{C}}-4\right) F^{2}\right] k_{2^{\circ} 12}$

where $k_{1^{\circ} 12}$ and $k_{2^{\circ} 12}$ are the group rate constants for reactions at primary and secondary ${ }^{12} \mathrm{C}$ atoms and $F$ is $F(\mathrm{Y})=1.23 .{ }^{15}$ The rate constant for the reaction of $\mathrm{OH}$ radicals with an $n$-alkane containing one ${ }^{13} \mathrm{C}$ atom can then be described by the sum of the products of the probabilities that a molecule is labeled at a specific site and the rate constants of the molecules with a ${ }^{13} \mathrm{C}$ atom at the given site. The latter can be calculated from the group rate constants. For a random distribution of the ${ }^{13} \mathrm{C}$ atom in the $n$-alkane we obtain the following relations, which will allow for determination of the group specific fractionation effects from experimental data:

$$
\begin{array}{cc}
N_{\mathrm{C}}=2 & k_{13}=k_{1^{\circ} 12}+k_{1^{\circ} 13} \\
N_{\mathrm{C}}=3 & k_{13}=(2 / 3)\left(F k_{1^{\circ} 13}+F k_{1^{\circ} 12}+k_{2^{\circ} 12}\right)+ \\
(1 / 3)\left(k_{2^{\circ} 13}+2 F k_{1 \circ 12}\right)(7 \mathrm{~b}) \\
N_{\mathrm{C}} \geq 4 \quad k_{13}=2 N_{\mathrm{C}}{ }^{-1}\left\{F k_{1^{\circ} 13}+F k_{1^{\circ} 12}+\right. \\
\left.\left[2 F+\left(N_{\mathrm{C}}-4\right) F^{2}\right] k_{2^{\circ} 12}\right\}+2 N_{\mathrm{C}}^{-1}\left\{F k_{2^{\circ} 13}+\right. \\
\left.\left[F+\left(N_{\mathrm{C}}-4\right) F^{2}\right] k_{2^{\circ} 12}+2 F k_{1^{\circ} 12}\right\}+ \\
\left(N_{\mathrm{C}}-4\right) N_{\mathrm{C}}^{-1}\left\{F^{2} k_{2^{\circ} 13}+\left[2 F+\left(N_{\mathrm{C}}-5\right) F^{2}\right] k_{2^{\circ} 12}+2 F k_{1^{\circ} 12}\right\}
\end{array}
$$

The two rate constants, $k_{12}$ and $k_{13}$, can now be combined with 
the introduction of the ${ }^{13} \mathrm{C}-\mathrm{SRR}$ values $\Delta_{1^{\circ} 13}=k_{1^{\circ}{ }^{\circ} 3}-k_{1^{\circ} 12}$, $\Delta_{2^{\circ} 13}=k_{2^{\circ} 13}-k_{2^{\circ} 12}$, and $\Delta_{3^{\circ} 13}=k_{3^{\circ} 13}-k_{3^{\circ} 12}$. To our knowledge, there are no published values for ${ }^{13} \mathrm{C}$ specific group rate constants, but the difference between rate constants for labeled and unlabeled compounds can be derived from our experimental results, $k_{13}-k_{12}=-k_{12} \epsilon /(1000+\epsilon)$, which allows for the derivation of estimates of the group specific values for ${ }^{13} \mathrm{C}$. For ethane, substituting eq $7 \mathrm{a}$ into eq $6 \mathrm{a}$ and replacing $k_{1^{\circ} 13}-k_{1^{\circ} 12}$ with $\Delta_{1^{\circ} 13}$ gives

$$
k_{13}-k_{12}=-k \epsilon /(1000+\epsilon)=\Delta_{1^{\circ} 13}
$$

where $k_{12}$ is assumed to be equal to $k$, which can then be either calculated using the SRR method, or taken from the literature. From the KIE results for ethane, an average value for $\Delta_{1^{\circ} 13}$ of $(-2.1 \pm 0.8) \times 10^{-15} \mathrm{~cm}^{3}$ molecule ${ }^{-1} \mathrm{~s}^{-1}$ is obtained when $\mathrm{OH}_{k}$ is taken from the literature value, ${ }^{4}$ and $(-2.3 \pm 0.9) \times$ $10^{-15} \mathrm{~cm}^{3}$ molecule ${ }^{-1} \mathrm{~s}^{-1}$ is obtained when ${ }^{\mathrm{OH}_{k}} k$ is derived using the SRR method. ${ }^{15}$ In both cases, the uncertainties were determined from the uncertainties of the measured KIE and the rate constants. For the SRR-determined rate constant, the uncertainty was estimated to be $\pm 50 \%$.

For propane, substituting eq $6 \mathrm{~b}$ into eq $7 \mathrm{~b}$ gives

$$
-k \epsilon /(1000+\epsilon)=(1 / 3)\left(2 F \Delta_{1^{\circ} 13}+\Delta_{2^{\circ} 13}\right)
$$

and for the general $n$-alkane with $N_{\mathrm{C}} \geq 4$, by combining eqs $6 \mathrm{c}$ and $7 \mathrm{c}$, we obtain

$$
\begin{aligned}
-k \epsilon /(1000+\epsilon)= & N_{\mathrm{C}}^{-1}\left\{2 F \Delta_{1^{\circ} 13}+\right. \\
= & \left.N_{\mathrm{C}}^{-1}\left[2 F+\left(N_{\mathrm{C}}-4\right) F^{2}\right] \Delta_{2^{\circ} 13}\right\} \\
& \left.\left(2 F-4 \Delta^{\circ}{ }^{2}\right) \Delta_{2^{\circ} 13}\right]+F^{2} \Delta_{2^{\circ} 13}(8 \mathrm{c})
\end{aligned}
$$

Thus, a plot of $-k \epsilon /(1000+\epsilon)$ against $N_{\mathrm{C}}{ }^{-1}$ for $N_{\mathrm{C}} \geq 4$ should give a straight line with a slope of $\left[2 F \Delta_{1^{\circ} 13}+\left(2 F-4 F^{2}\right) \Delta_{2^{\circ} 13}\right]$ and an intercept of $F^{2} \Delta_{2}{ }^{\circ} 13$. Using the $\mathrm{C}_{4}-\mathrm{C}_{8} n$-alkane KIE data, $\Delta_{1^{\circ} 13}=(0.0 \pm 1.2) \times 10^{-14}$ and $\Delta_{2^{\circ} 13}=(-1.4 \pm 0.3) \times 10^{-14}$, both in $\mathrm{cm}^{3}$ molecule ${ }^{-1} \mathrm{~s}^{-1}$ using the literature rate constant data, and $\Delta_{1^{\circ} 13}=(-0.2 \pm 1.3) \times 10^{-14}$ and $\Delta_{2^{\circ} 13}=(-1.4 \pm$ $0.3) \times 10^{-14}$, both in $\mathrm{cm}^{3}$ molecule $\mathrm{e}^{-1} \mathrm{~s}^{-1}$ using rate constants from SRR were derived.

In addition to the $n$-alkanes, there were a number of KIE results for branched and cyclic alkanes. From the cyclic alkanes, we further refined our estimation of $\Delta_{2^{\circ} 13}$, and from the branched alkanes, methylpropane and methylbutane, we determined $\Delta_{3^{\circ} 13}$ $=k_{3^{\circ} 13}-k_{3^{\circ} 12}$, where $k_{3^{\circ}}$ is the rate constant for the $\mathrm{H}$-atom abstraction from a $>\mathrm{CH}-$ group. First, for the simple cyclic hydrocarbons cyclopentane and cyclohexane, the total rate constant is the sum of the secondary rate constants for each hydrocarbon, with a ring strain factor $F_{5}=0.64$ on each carbon in the five-atom ring cyclopentane. As an example, the following relationship can be written for the reaction of $\mathrm{OH}$ radicals with a cyclopentane molecule containing only ${ }^{12} \mathrm{C}$ :

$$
\begin{aligned}
k_{12}=5 k_{2^{\circ} 12} F\left(-\mathrm{CH}_{2}-\right) & F\left(-\mathrm{CH}_{2}-\right) \\
& F(\text { five-member ring })=5 k_{2^{\circ} 12} F^{2} F_{5}
\end{aligned}
$$

Likewise, we can write an equation for the reaction with a cyclopentane molecule containing one carbon-13 atom:

$$
k_{13}=k_{2^{\circ} 13} F^{2} F_{5}+4 k_{2{ }^{\circ} 12} F^{2} F_{5}
$$

By combining eqs 9 and 10:

$$
-k \epsilon /(1000+\epsilon)=F^{2} F_{5} \Delta_{2^{\circ} 13}
$$

From the two KIE measurements for the reaction of cyclopentane with $\mathrm{OH}$ radicals we obtain $\Delta_{2^{\circ} 13}=(-9.4 \pm 0.7) \times 10^{-15}$ $\mathrm{cm}^{3}$ molecule $\mathrm{s}^{-1}$ using literature rate constant values, and $\Delta_{2^{\circ} 13}=(-8.6 \pm 0.6) \times 10^{-15} \mathrm{~cm}^{3}$ molecule ${ }^{-1} \mathrm{~s}^{-1}$ using the rate constant derived from SRR values. Likewise, from the single cyclohexane point, $\Delta_{2^{\circ} 13}=(-2.0 \pm 1.0) \times 10^{-14} \mathrm{~cm}^{3}$ molecule $\mathrm{e}^{-1} \mathrm{~s}^{-1}$ using the literature rate constant and $\Delta_{2^{\circ} 13}=$ $(-2.5 \pm 1.3) \times 10^{-14} \mathrm{~cm}^{3}$ molecule ${ }^{-1} \mathrm{~s}^{-1}$ using the SRRcalculated $k$ value. At this point, error-weighted averages can be calculated for $\Delta_{2^{\circ} 13}:(-9.7 \pm 0.7) \times 10^{-15} \mathrm{~cm}^{3}$ molecule ${ }^{-1}$ $\mathrm{s}^{-1}$ using the literature rate constant data and $(-8.8 \pm 0.6) \times$ $10^{-15} \mathrm{~cm}^{3}$ molecule ${ }^{-1} \mathrm{~s}^{-1}$ using SRR-calculated rate constants.

With the error-weighted average $\Delta_{2^{\circ} 13}$ value, $\Delta_{1^{\circ} 13}$ can now be determined for the propane results using eq $8 \mathrm{~b}$ : $(-3.3 \pm$ 1.2) $\times 10^{-15} \mathrm{~cm}^{3}$ molecule ${ }^{-1} \mathrm{~s}^{-1}$ using the literature rate constant data and $(-4.8 \pm 1.3) \times 10^{-15} \mathrm{~cm}^{3}$ molecule ${ }^{-1} \mathrm{~s}^{-1}$ using the SRR-determined rate constant for propane. The errorweighted average ${ }^{13} \mathrm{C}$-SRR values for $\Delta_{1^{\circ} 13}$, therefore, are $(-2.5$ $\pm 0.7) \times 10^{-15} \mathrm{~cm}^{3}$ molecule ${ }^{-1} \mathrm{~s}^{-1}$ using literature rate constant data and $(-3.1 \pm 0.7) \times 10^{-15} \mathrm{~cm}^{3}$ molecule ${ }^{-1} \mathrm{~s}^{-1}$ using SRRcalculated rate constants. The uncertainty in the primary ${ }^{13} \mathrm{C}$ SRR value is due in part to the uncertainty in the ethane KIE values, but also to the inclusion of the uncertainty of $\Delta_{2^{\circ} 13}$ in the $\Delta_{1}{ }^{\circ} 13$ determination from both the propane KIEs and the $\mathrm{C}_{4}-\mathrm{C}_{8}$ alkane KIEs.

Finally, to determine the isotopic effect on the structurereactivity relationship for tertiary carbon atoms, $\Delta_{3^{\circ} 13}$, the measured KIEs for methylcyclopentane, methylpropane, and methylbutane were used. From these three hydrocarbon KIEs, using the error-weighted averages for $\Delta_{1^{\circ} 13}$ and $\Delta_{2^{\circ} 13}$ determined from the room-temperature KIE measurements of the $n$-alkanes, cyclopentane, and cyclohexane, three values for $\Delta_{3^{\circ} 13}$ were determined: methylpropane $(-6.2 \pm 2.2) \times 10^{-14}[(-7.1 \pm$ $\left.2.5) \times 10^{-14}\right]$, methylbutane $(-2.5 \pm 0.7) \times 10^{-14}[(-3.0 \pm$ $\left.0.7) \times 10^{-14}\right]$, and methylcyclopentane $(-2.0 \pm 1.9) \times 10^{-14}$ $\left[(-2.3 \pm 1.9) \times 10^{-14}\right]$, all in $\mathrm{cm}^{3}$ molecule ${ }^{-1} \mathrm{~s}^{-1}$, with the values calculated using the SRR-determined rate constants in brackets. The error-weighted average for $\Delta_{3^{\circ} 13}$ is $(-2.8 \pm 0.6)$ $\times 10^{-14}$ using literature rate constants, and $(-3.2 \pm 0.7) \times$ $10^{-14}$ using SRR-determined rate constants, both in $\mathrm{cm}^{3}$ molecule $\mathrm{s}^{-1} \mathrm{~s}^{-1}$. The differences in isotopic reactivities for tertiary carbon atoms in the three branched alkanes is at least partly due to the limited number of results available for hydrocarbons with tertiary carbon atoms and the experimental errors of these values. However, it can also not be excluded that our assumption of identical ring strain factors for labeled and unlabeled cyclic alkanes is an oversimplification. The individual contributions as well as the final error-weighted averages for $\Delta_{1^{\circ} 13}, \Delta_{2^{\circ} 13}$, and $\Delta_{3^{\circ} 13}$ are summarized in Table 3.

The ${ }^{13} \mathrm{C}$-SRR values reported in Table 3 were determined using the one $n$-butane $+\mathrm{OH}$ KIE measurement from this work. Because of the large difference between the previous KIEs for this reaction and the KIE reported in this work, a repeat of the calculations for the ${ }^{13} \mathrm{C}$-SRR values was also made using the four previous $n$-butane KIEs to determine how sensitive the ${ }^{13} \mathrm{C}$ SRR values are to this difference. The values from this repeat calculation are all within $\pm 7 \%$ of the values determined using the KIE from this work. This is within the reported uncertainty of the measurements, showing that the overall ${ }^{13} \mathrm{C}$-SRR calculations are not highly sensitive to the uncertainty of the $n$-butane KIE. 
TABLE 3: Summary of the Carbon Isotope Structure Reactivity Relationship Values Determined from Measured ${ }^{13} \mathrm{C}-\mathrm{Kinetic}$ Isotope Effects in the Reactions of Alkanes with Hydroxyl Radicals at Room Temperature and $1013 \mathrm{mbar}$

\begin{tabular}{|c|c|c|c|c|c|c|}
\hline \multirow{2}{*}{$\begin{array}{l}\text { hydrocarbon or } \\
\text { hydrocarbon group }\end{array}$} & \multicolumn{2}{|c|}{$\begin{array}{c}10^{15} \Delta_{\mathrm{I}^{\circ} 13} \\
\mathrm{~cm}^{3} \text { molecule }^{-1} \mathrm{~s}^{-1}\end{array}$} & \multicolumn{2}{|c|}{$\begin{array}{c}10^{15} \Delta_{2^{\circ} 13} \\
\mathrm{~cm}^{3} \text { molecule }^{-1} \mathrm{~s}^{-1}\end{array}$} & \multicolumn{2}{|c|}{$\begin{array}{c}10^{15} \Delta_{3^{\circ} 13} \\
\mathrm{~cm}^{3} \text { molecule }^{-1} \mathrm{~s}^{-1}\end{array}$} \\
\hline & $k_{\text {literature }}{ }^{a}$ & $k_{\mathrm{SRR}}^{b}$ & $k_{\text {literature }}{ }^{a}$ & $k_{\mathrm{SRR}}^{b}$ & $k_{\text {literature }}^{a}$ & $k_{\mathrm{SRR}^{b}}$ \\
\hline ethane & $-2.1 \pm 0.8$ & $-2.3 \pm 0.9$ & & & & \\
\hline propane & $-3.3 \pm 1.2$ & $-4.8 \pm 1.3$ & & & & \\
\hline $\begin{array}{l}\mathrm{C}_{4}-\mathrm{C}_{8} \text { alkanes } \\
\text { cyclopentane } \\
\text { cyclohexane }\end{array}$ & $0 \pm 12$ & $-2 \pm 13$ & $\begin{array}{l}-14 \pm 3 \\
-9.4 \pm 0.7 \\
-20 \pm 10\end{array}$ & $\begin{array}{l}-14 \pm 3 \\
-8.6 \pm 0.6 \\
-25 \pm 13\end{array}$ & & \\
\hline methylpropane & & & & & $-62 \pm 22$ & $-71 \pm 25$ \\
\hline methylbutane & & & & & $-25 \pm 7$ & $-30 \pm 7$ \\
\hline methylcyclopentane & & & & & $-20 \pm 19$ & $-23 \pm 19$ \\
\hline error-weighted average & $-2.5 \pm 0.7$ & $-3.1 \pm 0.7$ & $-9.7 \pm 0.7$ & $-8.8 \pm 0.6$ & $-28 \pm 6$ & $-32 \pm 7$ \\
\hline
\end{tabular}

${ }^{a}$ Determined using literature rate constant values as shown in Table 2. ${ }^{b}$ Determined using rate constants derived from Structure Reactivity Relationship values. ${ }^{15}$
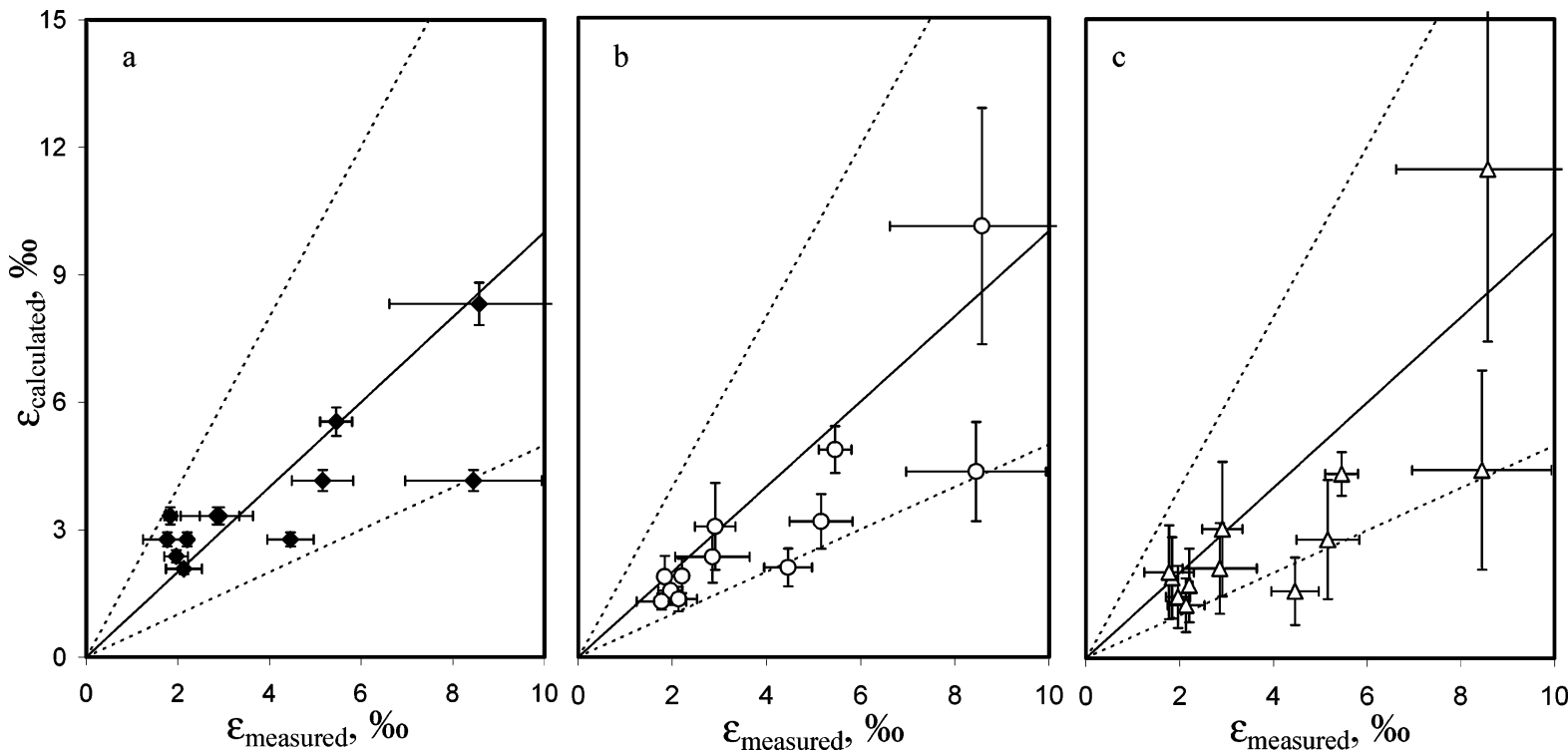

Figure 1. Comparison of the measured KIEs and the KIE values calculated using (a) $N_{\mathrm{C}}{ }^{-1}$ approximation, (b) ${ }^{13} \mathrm{C}$-SRR values calculated using literature rate constants, and (c) ${ }^{13} \mathrm{C}$-SRR values calculated using rate constants determined using SRR approximation for the gas-phase reactions of light alkanes with $\mathrm{OH}$ radicals. The solid lines show the $y=x$ line and the dotted lines show the $y=2 x$ and $y=0.5 x$ lines.

Using the three weighted averages for $\Delta_{1^{\circ} 13}, \Delta_{2^{\circ} 13}$, and $\Delta_{3^{\circ} 13}$, the primary, secondary, and tertiary values for the ${ }^{13} \mathrm{C}-\mathrm{SRR}$, KIEs can be calculated for alkane reactions that have not yet been measured. To check to the validity of this method, a comparison of the experimental alkane-OH KIEs from this work was made with the KIEs calculated using the $N_{\mathrm{C}}{ }^{-1}$ approximation and the average ${ }^{13} \mathrm{C}$-SRR values calculated from both literature rate constants and SRR-determined rate constants (Figure 1). In Figure 1b, the methylcyclopentane ${ }^{\mathrm{OH}_{k}} k$ from this work was used because no literature value is available.

From the 12 different alkane- $\mathrm{OH}$ reactions studied, all KIEs calculated using the $N_{\mathrm{C}}{ }^{-1}$ approximation and all KIEs calculated using the two sets of ${ }^{13} \mathrm{C}$-SRR values with the exception of the cyclohexane-OH KIE fall within a factor of 2 of the experimental KIE values. The $1 \sigma$ standard deviation in the percent differences between the experimental and calculated values are $37 \%, 23 \%$, and $29 \%$ for the KIEs calculated using $N_{\mathrm{C}}{ }^{-1}, k_{\text {literature }}$ ${ }^{13} \mathrm{C}$-SRR values, and $k_{\mathrm{SRR}}{ }^{13} \mathrm{C}$-SRR values, respectively. $R^{2}$ values calculated for the relationships between experimental values and calculated values are $0.63,0.67$, and 0.62 for the KIEs calculated using the $N_{\mathrm{C}}{ }^{-1}$ approximation, $k_{\text {literature }}{ }^{13} \mathrm{C}$ SRR values, and $k_{\mathrm{SRR}}{ }^{13} \mathrm{C}$-SRR values, respectively. Thus, the ${ }^{13} \mathrm{C}$-SRR determined KIEs are closer on average to the experimental value than those determined using a simple $N_{\mathrm{C}}{ }^{-1}$ relationship. SRR-calculated rate constants for $n$-alkane reactions with $\mathrm{OH}$ radicals are all higher than the accepted literature values, and as a result, the average value for $\Delta_{1^{\circ} 13}$ calculated using the $k_{\mathrm{SRR}}$ values is higher than the value calculated using the literature $k$ 's, and the value for $\Delta_{2^{\circ} 13}$ calculated using the $k_{\text {SRR }}$ values is lower than the value calculated using the literature $k$ 's. This leads to slight differences in the calculated KIEs. There is slightly better agreement between the KIEs calculated using literature rate constant data and the experimental KIEs (Figure $1 b)$. Because the SRR calculated $k$ 's are merely approximations and accurate to only within a factor of 2, the literature $k$ values, which are more widely accepted as the actual values, provide us with more accurate ${ }^{13} \mathrm{C}$-SRR values. The only calculated KIEs that are not within a factor of 2 of the experimental KIEs are for the reaction of cyclohexane with $\mathrm{OH}$. Because there is only one KIE measurement of the cyclohexane-OH KIE, it is difficult to determine the cause of the deviation. Our ${ }^{13} \mathrm{C}$-SRR method does not differentiate between cyclic and noncyclic secondary carbon atoms, which could contribute to this discrepancy.

There is also a significant deviation between the experimental and calculated values for two of the compounds containing tertiary carbon atoms; methylpropane and methylcyclopentane. For methylpropane, this deviation is independent of the calculation method, whereas for methylcyclopentane the deviation is only for the KIE calculated using the $N_{\mathrm{C}}{ }^{-1}$ approximation. These 
deviations are understandable for the $N_{\mathrm{C}}^{-1}$ approximation, derived solely from the $n$-alkanes. The deviation from the experimental KIE for the methylpropane reaction from the KIEs calculated using both of the ${ }^{13} \mathrm{C}$-SRR values is due in large part to the low number of KIE measurements that were made for hydrocarbons with tertiary carbon atoms. The two $\Delta_{3^{\circ} 13}$ values determined using the methylpropane KIE have much larger uncertainties and are a factor of 2 greater than the $\Delta_{3^{\circ} 13}$ values determined for the other compounds containing a tertiary carbon atom. The error-weighted average $\Delta_{3^{\circ} 13}$ value thus predicts a much smaller than the measured KIE. With additional KIE measurements of branched alkane $-\mathrm{OH}$ reactions, the uncertainty for $\Delta_{3^{\circ} 13}$ should decrease, improving the accuracy of the ${ }^{13} \mathrm{C}$ SRR calculations for compounds with tertiary carbon atoms.

Using the ${ }^{13} \mathrm{C}$-SRR values determined using the literature rate constants in combination with the group rate constants reported by Atkinson, ${ }^{15}$ the group KIEs for hydrogen atom abstraction by $\mathrm{OH}$ radicals were determined. Not accounting for errors within the group rate constants, because none are reported, the KIEs for hydrogen atom abstractions from primary, secondary, and tertiary carbon atoms are $\epsilon_{1^{\circ}}=18.7 \pm 5.2, \epsilon_{2^{\circ}}=10.5 \pm$ 0.7 , and $\epsilon_{3^{\circ}}=14.4 \pm 3.2$, all in $\%$ o.

Donahue et al. ${ }^{19}$ present an expression for the temperature dependence of the reaction of light alkanes with the $\mathrm{OH}$ radical, which is based on a simplified transition state theory. Their expression includes two vibration frequencies, one for the $\mathrm{CHO}$ and one for the $\mathrm{HOH}$ bend. Because the second vibration does not involve a carbon atom, it will not be directly affected by a change in the carbon atom mass. The frequency of the degenerate $\mathrm{CHO}$ bend is $300 \mathrm{~cm}^{-1}$. On the basis of the expression presented by Donahue et al., the site specific KIEs above correspond to changes in vibration frequency to $289 \pm 4$, $294 \pm 1$, and $292 \pm 2 \mathrm{~cm}^{-1}$, respectively. On the basis of the Teller-Redlich product rule, the frequency of the ${ }^{13} \mathrm{CHO}$ bend calculated from the $300 \mathrm{~cm}^{-1}{ }^{12} \mathrm{CHO}$ bend frequency is 288 $\mathrm{cm}^{-1}$. The corresponding KIE is $20.8 \%$. Thus, as a first approximation, our findings are consistent with the simplified transition state treatment of Donahue and colleagues. However, the treatment they present does not include a site dependence of the $\mathrm{CHO}$ bend frequency and thus does not predict any differences between the site specific KIEs. Our results indicate the existence of such differences although it should be noted that most of the site-specific KIE values have substantial uncertainties and the differences between them are only significant at a $1 \sigma$ confidence level. A possible qualitative explanation is a dependence of the $\mathrm{CHO}$ bend frequency on the $\mathrm{CH}$ bond strength in the alkane, which is decreasing from primary to tertiary carbon atoms but also changes in $\mathrm{CC}$ and $\mathrm{CCH}$ vibration frequencies, which are not treated explicitly in the transition state presented by Donahue et al., can contribute to the KIEs.

For the above determination and application of the carbon isotope SRR values, the basic assumption is that the ${ }^{13} \mathrm{C}$ distribution in the hydrocarbons is completely random. Strictly speaking, site-specific enrichment or depletion of ${ }^{13} \mathrm{C}$ will change the KIE value, although we expect that for hydrocarbons without artificial ${ }^{13} \mathrm{C}$ enrichment or depletion such an effect will be very small. To test this assumption, a calculation for consideration of site-specific enrichment was made. It is well established that carbon isotope effects are quite small, between a few per mille to a few 10 per mille. For our calculations, we changed the ${ }^{13} \mathrm{C}$ distribution in 2-methylbutane by $\pm 100 \%$ o $( \pm 10 \%)$, a likely overestimation of possible enrichment. With a random distribution, the KIE is calculated to be $2.73 \%$. With $\mathrm{a} \pm 10 \%$ enrichment of the primary carbon atoms, the resultant KIEs were $\pm 0.30 \%$ from the KIE determined for random ${ }^{13} \mathrm{C}$ distribution. Enrichments of $\pm 10 \%$ of the secondary and tertiary atoms resulted in even smaller differences. The reported KIE for methylbutane from this work, from two separate measurements, is $(2.91 \pm 0.43) \%$. Clearly, the expected impact of deviations from a random distribution of ${ }^{13} \mathrm{C}$ in hydrocarbons on carbon KIEs is less than the uncertainty of present day measurements.

Ethene KIE. To the authors' knowledge, the only previous measurements of alkene-OH KIEs were made by Rudolph et al. ${ }^{1}$ From their measurements, an inverse dependence on $N_{\mathrm{C}}$ can be approximated at $\epsilon(\% \circ)=(33.4 \pm 1.3) N_{\mathrm{C}}{ }^{-1}$ with an $R^{2}$ value of 0.878 . Adding the ethene-OH KIE $(18.6 \pm 2.9) \%$ o from this work, the inverse dependence becomes: $\epsilon(\%)=(34.9$ $\pm 1.2) N_{\mathrm{C}}{ }^{-1}$ with an $R^{2}$ value of 0.957 . This indicates very good agreement between the ethene KIE and the alkene KIEs previously reported.

\section{Conclusions}

For the 12 alkane-OH reaction KIEs that have been measured, the KIEs calculated using ${ }^{13} \mathrm{C}-\mathrm{SRR}$ values derived from the literature rate constant values for $k_{12}$ agree within a factor of 2 for all alkane- $\mathrm{OH}$ reactions except the $\mathrm{OH}$-oxidation of cyclohexane. The ${ }^{13} \mathrm{C}$-SRR concept allows for the calculation of the group specific $k_{13}$ values at $298 \mathrm{~K}: k_{1^{\circ} 13}=(1.342 \pm$ $0.002) \times 10^{-13}, k_{2^{\circ} 13}=(9.203 \pm 0.006) \times 10^{-13}$, and $k_{3^{\circ} 13}=$ $(1.898 \pm 0.009) \times 10^{-12}$, all with units $\mathrm{cm}^{3}$ molecule ${ }^{-1} \mathrm{~s}^{-1}$. The ${ }^{13} \mathrm{C}$-SRR values based on measured literature rate constants for $k_{12}$ result in KIEs that are in better agreement with the measured KIEs than the values determined using rate constants calculated using the SRR method. Using the group rate constant values reported by Atkinson ${ }^{15}$ as $k_{12}$, the $k_{12} / k_{13}$ ratios can be determined such that the group specific kinetic isotope effects are (all in \%o): $\epsilon_{1^{\circ}}=18.7 \pm 5.2, \epsilon_{2^{\circ}}=10.5 \pm 0.7$, and $\epsilon_{3^{\circ}}=$ $14.4 \pm 3.2$. The difference in the group kinetic isotope effect for the abstraction of a hydrogen atom from a primary carbon atom is statistically similar to the effect for abstraction from a tertiary carbon atom. However, there are indications that hydrogen atom abstractions from secondary carbon atoms lead to smaller carbon isotope fractionations than those reactions at primary and tertiary atoms, even within the uncertainties of our measurements.

The KIEs presented in this paper, including the measurement of the KIE for the reaction of ethene with $\mathrm{OH}$ radicals, are necessary for the accurate interpretation of ambient stable carbon isotope ratio measurements. The development of the ${ }^{13} \mathrm{C}-\mathrm{SRR}$ values allow for the calculation of alkane-OH KIEs not yet measured, although for branched and cyclic alkanes there are still significant uncertainties in the KIEs derived from the ${ }^{13} \mathrm{C}$ SRR.

In the measurement of ethene, the competitive reaction between $\mathrm{OH}$ and ozone decreased the reliability of the $\mathrm{OH}$ KIE measurement. For future alkene-OH KIE measurements, characterization of the predominant reactions within the chamber may be made possible by varying the concentration of $\mathrm{O}_{2}$ in the chamber. This would allow for better control over the production of ozone, and the subsequent competitive alkene reactions that may occur between $\mathrm{OH}$ radicals and ozone.

Acknowledgment. We sincerely thank D. Ernst and A. Chivulescu from the Meteorological Service of Canada for technical support and standard preparation. This research was supported financially by the Natural Sciences and Engineering 
Research Council of Canada (NSERC) and the Canadian Foundation for Climate and Atmospheric Sciences (CFCAS).

\section{References and Notes}

(1) Rudolph, J.; Czuba, E.; Huang, L. J. Geophys. Res. [Atmos.] 2000, $105,29329$.

(2) Placet, M.; Mann, C. O.; Gilbert, R. O.; Niefer, M. J. Atmos. Environ. 2000, 34, 2183.

(3) Sawyer, R. F.; Harley, R. A.; Cadle, S. H.; Norbeck, J. M.; Slott,

R.; Bravo, H. A. Atmos. Environ. 2000, 34, 2161.

(4) Atkinson, R.; Arey, J. Chem. Rev. 2003, 103, 4605.

(5) Rudolph, J.; Czuba, E. Geophys. Res. Lett. 2000, 27, 3865

(6) Rudolph, J. Tropospheric Chemistry and Composition: Aliphatic Hydrocarbons. In Encyclopedia Atmospheric Sciences; Holton, J. R., Pyle, J., Curry, J. A., Eds.; Academic Press: London, 2003; p 2355.

(7) Rudolph, J.; Anderson, R. S.; von Czapiewski, K.; Czuba, E.; Ernst, D.; Gillespie, T.; Huang, L.; Rigby, C.; Thompson, A. E. J. Atmos. Chem. 2003, 44, 39.

(8) Tsunogai, U.; Yoshida, N.; Gamo, T. J. Geophys. Res. [Atmos.] 1999, 104, 16033
(9) Rudolph, J.; Czuba, E.; Norman, A. L.; Huang, L.; Ernst, D. Atmos. Environ. 2002, 36, 1173.

(10) Saito, T.; Tsunogai, U.; Kawamura, K.; Nakatsuka, T.; Yoshida, N. J. Geophys. Res. [Atmos.] 2002, 107, ACH 2/1.

(11) Thompson, A.; Rudolph, J.; Rohrer, F.; Stein, O. J. Geophys. Res. [Atmos.] 2003, 108, ACH 1/1.

(12) Anderson, R. S.; Czuba, E.; Ernst, D.; Huang, L.; Thompson, A. E.; Rudolph, J. J. Phys. Chem. A 2003, 107, 6191.

(13) Noyes, W. A. $n$-Butyl nitrite. In Organic Syntheses; Blatt, A. H., Ed.; Wiley: New York, 1943; Vol. 2, p 108.

(14) Iannone, R.; Anderson, R. S.; Rudolph, J.; Huang, L.; Ernst, D. Geophys. Res. Lett. 2003, 30, 17/1.

(15) Atkinson, R. J. Phys. Chem. Ref. Data 1997, 26, 215.

(16) Droege, A. T.; Tully, F. P. J. Phys. Chem. 1987, 91, 1222.

(17) Tully, F. P.; Droege, A. T.; Koszykowski, M. L.; Melius, C. F. J. Phys. Chem. 1986, 90, 691.

(18) Iannone, R.; Anderson, R. S.; Vogel, A.; Rudolph, J.; Eby, P.; Whiticar, M. J. J. Atmos. Chem. 2004, 47, 191.

(19) Donahue, N.; Anderson, J. G.; Demerjian K. L. J. Phys. Chem. A 1998, 102, 3121 . 